\title{
When is the Spirit of Capitalism Effective for Economic Development?
}

\author{
Shiro Kuwahara ${ }^{1}$ \\ ${ }^{1}$ School of Economics, University of Hyogo, Kobe, Japan \\ Correspondence: Shiro Kuwahara, School of Economics, University of Hyogo, Kobe, Nishi Ward \\ Gakuen-nishimachi, Japan. Tel: 81-78-794-5409. E-mail: kuwahara@econ.u-hyogo.ac.jp
}

Received: December 16, 2017

Accepted: January 24, 2017

Online Published: January 30, 2018

doi:10.5539/ijef.v10n3p70

URL: https://doi.org/10.5539/ijef.v10n3p70

\begin{abstract}
By incorporating endogenous innovation and wealth preference into the growth model, this paper aims to combine two important factors of economic development - "creative destruction," as emphasized by Schumpeter (1912) and modelized by Aghion and Howitt (1992), and the "spirit of capitalism," proposed by Weber (1905). Zou (1994) introduced this "spirit of capitalism" into the modern growth analysis by reinterpreting the Kurz (1968) model, wherein a preference on asset accumulation is introduced into the Ramsey model. By uniting these two factors, we obtain the result that this preference basically stimulates the long-term growth rate, and that it is effective when the economy has a too low innovation efficiency. However, the effect is small for an economy with a sufficiently high innovation efficiency.
\end{abstract}

Keywords: spirit of capitalism, wealth preference, R\&D-based growth, no-growth trap

\section{Introduction}

The mechanism of economic development has been an important theme since the fast stage of political economies. This research is a theoretical trial, which takes the first step to incorporate two early but important perspectives of economic development - those of Weber (1904/1905) and Schumpeter (1912) - to analyze economic development (and no/under development). One of the two factors of analysisis Weber (1904/1905)'s the "spirit of capitalism," and the other is Schumpeter (1912)'s "creative destruction."

The main concept proposed by Schumpeter has been confirmed as early as the 1950s by Solow's growth accounting (Solow, 1957), but its modelization was delayed to as late as the 1990s. In the early 1990s, the R\&D-based growth model was finally developed by Romer (1990), Grossman and Helpman (1991), and Aghion and Howitt (1992). They endogenized the technological progress derived from R\&D activities and demonstrated a mechanism for the long-term growth of a capitalist economy. The other concept that the "spirit of capitalism" engenders modern economic development is proposed by Weber (1904/1905), and it is described as follows: the propensity for wealth accumulation is initially formed by religious belief on the Protestant Ethic and it bears the modern capitalistic economic growth. Thus, Weber (1904/1905) emphasized religious ascetic values, termed as the "Protestant Ethic," (Note 1) which is an ascetic endeavor for self-help in practicing and executing one's Beruf (calling) with frugality, and states that the accumulation of wealth is the result of religiousness. This implies that accumulation itself becomes the objective. This concept of Weber's yielded some interesting studies, for example, Blum and Dudley (2001), Barro and McCleary (2003), and Noland (2003) as empirical studies, and Zou $(1994,1995,1998)$ as theoretical studies, wherein Weber's "spirit of capitalism" is attempted to be captured by introducing an additional factor into the utility function. Zou (1994) gives the new interpretation of the Kurz (1968) model as the formulation of Weber's "spirit of capitalism." The Kurz (1968) model merged the preference of capital accumulation, which we term "wealth preference" in this study (Note 2), into the newly developed (at that time) neoclassical growth model, as expressed by Cass (1965) and Koopmans (1965), and Zou (1994) pointed out that the wealth preference of Kurz (1968) captures the concept of Weber's "spirit of capitalism". Cole, Mailath, and Postle waite (1992) suggest that this type of preference can be obtained as a reduced-form specification to capture people's concern for the irrelative wealth position or status in society, and then, based on these growth theories, the trial of incorporating Weber's concept into a new growth theory is made. Carroll (2000) uses Zou's interpretation of the "spirit of capitalism," and provides an explanation for the fact that richer households have higher lifetime saving rates, as reported by Dynan, Skinner, and Zeldes (1996), and Lillard and 
Karoly (1997). Weber's concept has not been soactively analyzed, as compared with Schumpeter's concept, which has witnessed several economic growth studies. One reason for this lack might be the controversial empirical support. Empirical studies on the relationship between religion and economy have been gathering attention recently, and we can refer to Barro and McCleary (2003) who uncover a relationship between religious belief, religious propensity, and economic growth.

However, some results are negative. For example, Sala-i-Martin, Doppelhofer, and Miller (2004) identified a relationship between religious affiliations and growth but found no relationship between the intensity of belief and per capita growth. In addition, Durlauf, Kourtellos, and Tan (2006) evaluated the results of Barro and McCleary (2003) and found that the robustness is weak, and Cantoni (2009) found no effects of Protestantism on economic growth by using population figures in a dataset comprising 272 cities for the years spanning 1300 1900.

However, these studies investigated the relationship between religion and the mere results of economic growth. Alternatively, by using the Schumpeterian growth theory, the present study tries to derive the condition between generation of innovation, which bears long-term positive growth, and the intensity of the "spirit of capitalism," for which we use the approach proposed by Zou (1994). Following this line, we refer to some recent studies, such as Dorius (2012), Zhou (2016) and Rehme (2017) (Note 3). This approach incorporates an additional humanistic property in addition to the traditional setup, so it is not limited by regional affiliation but rather broad propensity. This trial is consistent with the modern empirical studies that try to incorporate every phenomenon to account for the economic growth (Note 4).

Furthermore, although it does not seem to be the usual combination of Weber and Schumpeter, but these two economists did share some perspectives. One of them is the view of an economic agent. Schumpeter states the inducement to entrepreneurs, to whom he attaches the central role in capitalism, namely innovation-driven economy, as follows: "In one sense, he [an entrepreneur] may indeed be called the most rational and the most egotistical of all... And in no sense is his characteristic motivation of the hedonist kind ... Then it is no longer true that our type is acting on a wish to satisfy his wants." (Schumpeter, 1912, translated into English in 1951.) When Schumpeter stated thus, his view of economic man was obviously and smoothly connected with that of Weber, who designated the "spirit of capitalism" as the main engine of capitalism's development. Thus, both Schumpeter and Weber agree that entrepreneurs, who perform capitalistic development, seem to be irrational if we assume that they derive their utility only from their consumption activities, because in fact, they seem to gain their satisfaction from accumulation itself.

Thus, the model studied in the present paper follows the above two lines. Namely, we develop a model with an 'a la Kurztype wealth preference, which captures Weber's "spirit of capitalism," and an 'a la Aghion and Howitt-type endogenous technological change through the improvement of the quality of intermediate goods, which modelizes Schumpeter's notion of "creative destruction." Therefore, in this study, we unite the the "spirit of capitalism" as the preference for wealth accumulation with the Shumpeterian growth model, and inquire the condition that the "spirit of capitalism" is effective on economic development and growth.

The obtained results are as follows: First, we show that the "spirit of capitalism" captured by wealth preference basically stimulates the long-term economic growth rate. Second, if R\&D efficiency is too low, the economy has a possibility of being stuck in poverty traps and in this case, a sufficient increase in the "spirit of capitalism" can make the economy's steady state one with long-term endogenous growth. Last, the effectiveness of the "spirit of capitalism" on growth enhancing is decreasing.

The rest of the paper is organized as follows: Section 2 develops the model, and Section 3 presents the derivation of the steady state of the model and explains the properties obtained from the model. Finally, Section 4 concludes the paper.

\section{The Model}

The model of this study consists of a household with the spirit of capitalism and a production sector with endogenous technological progress. The time is continuous, and the final goods are used as a numeraire.

\subsection{Weberian Household}

The Weber economy should consist of a representative household with a preference for wealth accumulation, which, following Kurz (1968), is captured by the assumption that the household derives utility from both consumption $(c)$ and per capita wealth, the financial asset in this study, $(A)$. Thus, the representative agent in this economy has the following utility: 


$$
U=\int_{0}^{\infty} u(c, A) e^{-\rho t} d t=\int_{0}^{\infty} \frac{\left(c^{\frac{1}{1+\beta}} A^{\frac{\beta}{1+\beta}}\right)^{1-\sigma}-1}{1-\sigma} e^{-\rho t} d t
$$

where $\rho$ and $u(c, A)$ are the subjective discount rate and an instantaneous utility function of the representative household, respectively. Furthermore, $\beta(\geq 0)$ is the parameter that captures the intensity of wealth preference against consumption. When $\beta=0$, there is no wealth preference, and the model corresponds to the usual Ramsey-type utility structure.

The representative household has the budget constraint: $A^{\circ}=r A+w-c-n A$, where $r$ and $w$ are the interest rate and wage rate, respectively. $n$ is a population growth rate that is assumed to be non-negative throughout the study.

Under this specification, the optimizing condition for the consumption growth rate corresponds to the Euler equation in the usual Ramsey models, and is given as follows:

$$
\sigma \frac{\dot{c}}{c}+(1-\sigma) \frac{\beta}{1+\beta} \frac{\dot{x}}{x}+\rho=r-n+\beta \chi
$$

where $\chi \equiv c / A$, which denotes the consumption-asset ratio. By comparison with the usual Euler equation of the Ramsey

model, this study is found to have two additional terms related by $\chi ; \beta /(1+\beta)(1-\sigma) \dot{x} / \chi$, and $\beta \chi$. The former is related to the growth rate and the latter to the earning rate of asset (or marginal rate of transformation).

Eq. (2) implies $\dot{x}=0$ in a steady state; therefore, the former term related to growth rate of $\chi$ is canceled out in the steady state and the latter term related to $\chi$ produces effects on the long-term growth conditions.

\subsection{Schumpeterian Production}

A Schumpeter economy is one where innovation is undertaken. This study adopts an Aghion and Howitt (1992)-type Schumpeterian growth model with an intermediate goods quality improvement structure.

\subsubsection{Production}

In the final goods production, the model includes three sectors: final goods, intermediate goods, and R\&D. It also contains four production factors: labor, final goods, intermediate goods, and knowledge. Labor is a unique human resource in this study; it is inelastically supplied by the population $(L)$ and is used in final goods production $(L Y)$ or R\&D activities $(L A)$, therefore, $L=L Y+L A$. The final goods are produced by labor and the cluster of intermediate goods, where the cluster is specified as follows. Each type of intermediate good is indexed as $i \in(0, N)$, where $N$ is assumed a sufficiently large constant that is given. Each type of intermediate good has a vertical quality level known as a "quality ladder," where each quality level is assumed to be $\lambda, \lambda^{2}, .$. , $\lambda^{M_{i}}$ for the quality index $m i=1,2, \ldots, M i$, respectively, where $\lambda(>1)$ is the exogenously given "width" of one innovation. Thus, we specify the production function of final goods as $\left.Y=L^{1-\alpha} \int_{0}^{N}\{q(i) x(i)\}^{\alpha}\right) d i(\alpha \in$ $(0,1))$, where $L_{Y}$ and $x(i)$ respectively denote the labor supply allocated to final goods

production, and the $i$ th sector's intermediate goods input. $q(i)$ is the used quality level of $i$ th intermediate goods, and in this arrangement improvement in the quality of intermediate goods is the engine of the long-term growth.

The final goods are produced by utilizing labor and the cluster of intermediate goods, and are used as capital investment $\left(K^{*}\right)$ or consumed as consumption goods $(C)$; therefore, $Y=C+\dot{\mathrm{K}}$.

Thus, one unit of an intermediate good ranked $m$ is equivalent to $\lambda$ units of an intermediate good ranked $m-1$. Thus, the quality of the cluster of intermediate goods is the source of economic growth in this study; therefore, the productivity of intermediate goods can be regarded as knowledge in this economy. Thus, we denote the current highest quality of the $j$ th sector as $q(i)$; therefore, $q(i) \equiv \lambda^{M i}$. We also denote the $i$ th sector's next

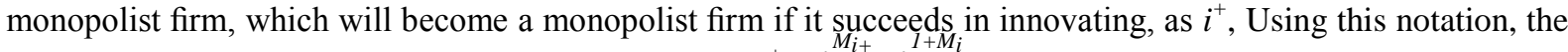
quality after one additional innovation is denoted as $q\left(i^{+}\right)=\lambda^{M_{i+}}=\lambda^{1+}$

In this setting, each quality level $m$ has efficiency $q^{m}$, and thus, the intermediate goods that are one grade higher in terms of quality are $q$ times more efficient than those that are one grade lower. Since quality-adjusted intermediate goods within the same sector are perfect substitutes, there exists demand for quality goods with the 
lowest quality-adjusted cost. Thus, the intermediate goods that are in demand are always those with the highest quality.

We assume that the final goods production has constant returns to scale and there is no complementarity among intermediate goods. Denoting the demand of the $i$ th intermediate goods sector, which currently has the highest quality, as $x(i)$, we can specify the production function of final goods $Y$ as follows:

$$
\left.Y=L_{Y}^{1-\alpha} \int_{0}^{N}\{q(i) x(i)\}^{\alpha}\right) d i, \quad 0<\alpha<1
$$

where $L_{Y}$ is the labor supply allocated to final goods production.

The first-order condition (FOC) of production is obtained as $\frac{\partial Y}{\partial x(i)}=p(i)$, and $\frac{\partial Y}{\partial L_{Y}}=w Y$, where $p(i)$ and $w Y$ are the price of the $i$ th intermediate goods of the highest quality and the wage rate offered in the final goods production sector, respectively. R\&D firms facilitate technological progress; they create a design that is one grade higher in terms of quality than the incumbent highest quality design. The R\&D activities of the firms take place at the beginning of each period, and the results are immediately evident. A successful research firm retains exclusive rights for the new higher quality intermediate goods. This exclusive right is referred to as a "patent."

In this study, one unit of the intermediate good of production is generated from $\eta$ units of final goods. Hence, the firm producing the $i$ th intermediate good maximizes the profit such that

$$
\pi(i)=p(i) x(i)-\eta r x(i)
$$

The FOC of the monopoly firm in the $i$ th sector with quality $M i$ yields the following:

$$
x(i)=\left[\frac{a^{2}}{\eta r}\right]^{\frac{1}{1-\alpha}} L_{Y} q(i)^{\frac{\alpha}{1-\alpha}} \text {, and } p(i)=\frac{\eta r}{\alpha}
$$

With regard to monopolistic pricing, we have the following three conditions. First, each unit of the highest quality good is equivalent to $\lambda(>1)$ units of the good with the next best quality. Second, a good that is one grade lower than the highest quality good is supplied at a marginal cost $\eta$ because the patent for this quality grade expires. Third, the different quality grades are perfect substitutes if they are weighted by the quality level. Based on the above conditions, it follows that $p(i)<\lambda \eta$ is necessary for the firm to create the highest quality good to monopolize the demand for that good. Therefore, a combination of (5) and $p(i)<\lambda \eta$ indicates that (5) is the optimal condition under the assumption that $1 / \alpha<\lambda$. The following discussion is developed such that it satisfies the present assumption.(Note 5) Thus, only the highest quality goods are supplied.

The aggregate index of quality is defined as follows:

$$
Q \equiv \int_{0}^{N} q(i)^{\frac{\alpha}{1-\alpha}} d i
$$

Here, we introduce a new variable $K$, which denotes aggregate capital accumulation. Aggregating (5) across sectors yields

$$
K=\eta \int_{o}^{N} x(i) d i=\eta \int_{o}^{N} x(i) d i=\eta\left[\frac{\alpha^{2}}{\eta r}\right]^{\frac{\alpha}{1-\alpha}} L_{Y} Q
$$

By using (3), (4), (5), and (7), we have the interest rate $r$, output $Y$, the profit of the $i$ th sector monopoly firm with patent are respectively obtained as follows:

$$
\begin{gathered}
r=\alpha^{2} \eta^{-\alpha} K^{\alpha-1} L_{Y}^{1-\alpha} Q^{1-\alpha}, \mathrm{Y}=\eta^{-\alpha} K^{\alpha} L_{Y}^{1-\alpha} Q^{1-\alpha} \\
\text { and } \pi(i)=(1-\alpha) \alpha \frac{Y}{Q} q(i)^{\frac{\alpha}{1-\alpha}}
\end{gathered}
$$

\subsubsection{R\&D Activities}

It is presumed that R\&D activities for the purpose of innovating higher quality levels are conducted using labor, and the success of R\&D stochastically depends on the labor input. As for the behavior of the R\&D firm and aggregate quality index, we basically follow Barro and Sala-i-Martin (1995 Ch7).

When innovation occurs in a sector, the value of firm $v(i)$ is given by the current value of the profit sequence, and the probability that firm $j$ in that sector will be granted a patent is assumed proportional to its share of the R\&D input in the $i$ th sector (that is, $L A(i)^{j} / L A(i)$, where $L_{A}(i)^{j}$ and $L A(i)$ represent the R\&D input for the $i$ th sector by 
firm and the aggregate R\&D input for the $i$ th sector, respectively).

Therefore, the above assumptions show that the profit for sector $i$ of $\mathrm{R} \& \mathrm{D}$ firm $j$ is

$$
\max _{L_{A}^{(i)^{j}}} \frac{\mu(i) L_{A}^{(i)^{j}}}{L_{A}^{(\mathrm{i})}} v(i)-w_{A} L_{A}^{(i)^{j}}
$$

where $w A$ is the wage rate offered in the R\&D sector and $v(i)$ is the expected current value of the profit of the $i$ th good's production. The presence or absence of investment in R\&D activities is determined as follows. If $\frac{\mu_{A}(i)^{j}}{L_{A}(i)} v(i)<w_{A} L_{A}(i)^{j}$ holds, then R\&D is not profitable. Consequently, the R\&D input stops and equilibrium is attained without R\&D; therefore, the probability of R\&D success is 0 , that is, $L A(i)=0$ and $\mu(i)=0$. In the case of no R\&D, the quality of the intermediate goods would remain constant over time. If $\frac{\mu L_{A}(i)^{j}}{L_{A}(i)} v(i)=w_{A} L_{A}(i)^{j}$, a positive amount of labor would be devoted to $R \& D$ activities and the market would be in equilibrium. Furthermore, no arbitrage on the labor market leads to $w \equiv \max \{w Y, w A\}$. Therefore, in equilibrium, $w=w Y=$ $w A$ must hold if R\&D takes place, and $w=w Y>w A$ must hold if there is no R\&D. Thus, from the FOCs of the production, $w=(1-\alpha) Y / L_{Y}$ holds. Under the positive $\mathrm{R} \& \mathrm{D}$ (namely, $L_{A}(i)>0$ and $\mu(i)>0$ ), the abovementioned points can be summarized as follows:

$$
v(i)=\frac{1-\alpha}{\mu(i)} \frac{Y}{L_{Y}} L_{Y}(i)
$$

First, we assume that the former case depicts a steady state with positive long-term growth. The asset equation derived from the value of the firm is made as follows:

$$
\begin{gathered}
r v(i)=\pi(i)+\dot{v}(i)-\mu\left(i^{+}, v(i),\right. \text { or equivalently } \\
\mathrm{r}+\mu\left(i^{+}\right)=\frac{\pi(i)}{v(i)}+g_{v(i)}
\end{gathered}
$$

where $\mu\left(i^{+}\right)$denotes the R\&D success probability of this sector with one-grade higher quality.

Substituting (8) and (9) into (10), we obtain

$$
r+\mu\left(i^{+}\right)=\frac{\mu(i)(1-\alpha) \alpha \frac{Y}{Q} q(i)^{\frac{\alpha}{1-\alpha}}}{(1-\alpha) \frac{Y}{L_{Y}} L_{A}(i)}+\frac{\dot{v}(i)}{v(i)}
$$

We assume that the $i$ th sector's innovation success is determined by two relative factors: relative R\&D labor input share $L_{A}(i) / L$ and $i$ th sector's relative quality rank $q(i) / Q$. The former has a positive effect and the latter, negative. We further assume that these two effects are linearly related to the Poisson arrival rate of innovation success. The consequent equation is then specified as follows: (Note 6)

$$
\mu(i)=\xi \frac{L_{A}(i) / L}{q(i) \frac{\alpha}{1-\alpha / Q}}, \xi>0 .
$$

We assume symmetric equilibrium across intermediate goods sectors. Using $\frac{\dot{v}(i)}{v(i)}=n$ in a steady state, which can be obtained from (8) and (12). (11) in a steady state is given as follows:

$$
\mu=\alpha \xi l+n-r
$$

where $l \equiv L Y / L$ denotes the rate of labor division on final goods production.

(12) and (13) yield

$$
L_{A}(i)=\frac{q(i)^{\frac{\alpha}{1-\alpha}} L}{\xi Q}(\alpha \xi 1+\mathrm{n}-r)
$$

Aggregating (14) over $i$ yields the aggregate R\&D spending, denoted by $L A$ :

$$
L_{A}=(1-l) L=\int_{0}^{N} L_{A}(i) d i=L\left[\alpha l-\frac{r-n}{\xi}\right]
$$

Hence, $L_{A}$ is proportional to $L$ for a given variable $r$. (15) immediately yields the relationship between $r$ and $l$ as $r$ 
$-n=\{(1+\alpha) l-1\} \xi$ or equivalently $l=\frac{1}{1+\alpha}\left(\frac{r-n}{\xi}+1\right)$, and from this equation and (13), we obtain the following equilibrium $\mu$ as a function of $l$ :

$$
\mu=\xi(1-l) \text {. }
$$

Thus, the innovation probability of the economy is linear against the rate of labor input on R\&D activity.

\section{Long-Term Growth and Its Properties}

Because our concern regarding long-term growth, we restrict ourselves to steady state analysis. From the dynamics of $Q$ defined in (6), the increment in the $i$ th sector's innovation $R(i) \equiv q\left(\mathrm{i}^{+}\right)^{\frac{\alpha}{1-\alpha}}-q(\mathrm{i})^{\frac{\alpha}{1-\alpha}}$ is calculated as $R(i)=q(\mathrm{i})^{\frac{\alpha}{1-\alpha}}\left(\lambda^{\frac{\alpha}{1-\alpha}}-1\right)$. Therefore, the aggregate dynamics of $Q$ are

$$
E(\dot{\mathrm{Q}})=\int_{0}^{N} R(i) d i=\mu\left(\lambda^{\frac{\alpha}{1-\alpha}}-1\right) Q
$$

From (16) and (17), the dynamics of $Q$ as a function of $l$ are derived as follows:

$$
g_{Q}=\mu\left(\lambda^{\frac{\alpha}{1-\alpha}}-1\right)=\xi(1-l) \Lambda
$$

where $\Lambda \equiv \lambda^{\frac{\alpha}{1-\alpha}}-1>0$ and $g_{Z} \equiv \dot{Z} / Z$. Since $\partial \Lambda / \partial \lambda>0, \Lambda$ is the parameter that immediately captures the scale of an innovation.

From (9) and (12), the aggregate market value of R\&D firms $V$ is calculated as

$$
V=\int_{0}^{N} v(i) d i=\int_{0}^{N} \frac{w L_{A}(i)}{\mu(i)} d i=\frac{(1-\alpha) Y}{\xi l}
$$

where $w=(1-\alpha) Y /(l L)$.

We assume symmetric equilibrium for the household, and the assets of this economy consist of the equity of R\&D firms $V$, derived in (19), and capital stock $K$. The representative household in this study has a risk-averse attitude and therefore, the household seeks to diversify its portfolio by including all brands. Accordingly, the per capita asset holding $A$ in this study can be denoted as

$$
A^{*}=\frac{V^{*}+K^{*}}{L^{*}}=\left[\frac{(1-\alpha) r^{*}}{\xi l^{*} \alpha^{2}}+1\right] k^{*}
$$

where $k \equiv K / L$ denotes the per capita capital stock, and $r=\alpha^{2} y / k$ is derived from (8). The resource constraint of the final goods $Y=C+\dot{K}$ gives $c=y-\dot{k}-n k$. From this and (8), we obtain the following:

$$
C^{*}=\left(\frac{r^{*}}{\alpha^{2}}-g_{Q}^{*}-n\right) K^{*}, \text { and } g_{c}^{*}=g_{k}^{*}=g_{y}^{*}=g_{Y}-n=g_{Q}^{*}
$$

From (13) and (16), we can give the steady state interest rate $r^{*}$ as a function of the labor allocation rate $l^{*}$ :

$$
r^{*}=(1+\alpha) \xi l^{*}+n-\xi
$$

It should be noted that because the value of a firm cannot be negative, the non-negativity condition $V$ and (20) yield $\frac{(1-\alpha) r}{\xi l \alpha^{2}}>0$, namely $r>0$. This condition and (22) yield the following:

$$
l^{*}>\frac{1}{1+\alpha} \frac{\xi-n}{\xi}\left(\equiv \underline{l}_{v}\right)
$$

Substituting $\dot{X}^{*}=0$ and $g_{c}^{*}=\xi\left(1-l^{*}\right) \Lambda$ from (18) and (21), and (22) into the Euler equation (2), we can obtain the equilibrium condition for $l$ :

$$
\chi=\Gamma(l)=-\frac{\bar{\Gamma} \xi}{\beta}(l-\bar{l})
$$


Where $\bar{l} \equiv \frac{1+\sigma \Lambda+\rho / \xi}{1+\alpha+\sigma \Lambda}(>0)$ and $\bar{\Gamma} \equiv 1+\alpha+\sigma \Lambda$. It should be noted that $(\bar{l}, 0)$ is the fixed point of $\Gamma(1)$ for the parameter $\beta$. Substituting (18), (20), (21), and (22) into the definition of $\chi=c / A$ yields

$$
\chi=\chi(l)=\bar{\chi} \xi-\frac{l-\underline{l}_{c}}{l-\underline{l}_{A}} l \text {, for } \max \left[0, \underline{l}_{c}\right]<l \leq 1,
$$

where $\bar{\chi} \equiv 1+\alpha+\alpha^{2} \Lambda, \underline{l}_{c} \equiv \frac{\left(1+\alpha^{2} \Lambda\right) \xi-\left(1-\alpha^{2}\right) \mathrm{n}}{\bar{\chi} \xi}$ and $\underline{l}_{A} \equiv \frac{1-\alpha}{\xi}(\xi-n)$. The domain $\max \left[0, \underline{l}_{c}\right]<l$ stems from the positive condition of consumption. In this domain, $\chi^{\prime}(\cdot)>0$ always holds.

These two equations determine $l$ in the steady state, and are depicted in Fig. 1. (See Appendix B for detailed derivations.) Thus, we obtain the result that the increase in $\beta$ raises the growth rate in the steady state through a decrease in $l^{*}$ as long as the non-negativity conditions hold. This is summarized and proved as follows:

Proposition 1 As long as an economy has a steady state with positive long-term endogenous growth, a more intense wealth preference increases the economic growth rate.

Proof. Since $\frac{\partial g_{Q}}{\partial l}<0$, proving $\frac{\partial g_{Q}}{\partial \beta}>0$ is equivalent to proving $\frac{\partial l}{\partial \beta}<0$.

Differentiation of (24) and (25) yields

$$
\chi d \beta+\beta d \chi=-\bar{\Gamma} d l \text { and } d \chi=\bar{\chi} \xi\left[1+\frac{\underline{l}_{A}\left(\underline{l}_{c}-\underline{l}_{A}\right)}{\left(l-\underline{l}_{A}\right)^{2}}\right] d l
$$

It should be noted that the sign of $1+\frac{l_{A}\left(l_{C}-\underline{l}_{A}\right)}{\left(l-\underline{l}_{A}\right)^{2}}$ is always positive (See Appendix B).

Eliminating $d \chi$ from these two derivatives, we obtain

$$
\frac{d l^{*}}{\partial \beta}=-\chi\left(l^{*}\right)\left\{\bar{\Gamma}+\left[1+\frac{\underline{l}_{A}\left(\underline{l}_{C}-\underline{l}_{A}\right)}{\left(l-\underline{l}_{A}\right)^{2}}\right] \beta \bar{\chi} \xi\right\}^{-1}<0
$$

Thus, we can conclude that $\frac{d l^{*}}{\partial \beta}<0$ always holds for $l>\max \left[0, \underline{l}_{c}\right]$, which gives $\chi(l)>0$. (Q.E.D.)

It can be said that this property reflects what Weber called the "spirit of capitalism," and it is shown to be basically held. Then, we investigate the condition of occurrence of poverty traps. This is the case of $l^{*}>1$. Thus, we have as follows:

Proposition 3 An economy has a possibility of a poverty trap if $\xi<\alpha \rho$. In addition to this, a lower $\beta$ causes poverty traps.

Proof. If $l<1$, the steady state value of $l^{*}$ always satisfies $l^{*}<1$, that is, positive growth is always realized. Therefore, poverty traps may emerge $l>1$, and this condition is transformed into $\xi<\alpha \rho$. The former part is, thus, proved. The latter part is proved as follows. The condition $l^{*}<1$ is transformed into $\chi(1)>\Gamma(1)$, which gives

$$
\beta>\underbrace{\frac{\alpha \xi+n(1-\alpha)}{\alpha \xi+n\left(1-\alpha^{2}\right)}}_{\equiv \Delta}\left(\frac{\rho}{\xi}-\alpha\right)(\equiv \Omega(\xi))
$$

$\alpha \in(0,1)$ yields $\Delta \in(0,1)$; therefore, we can obtain a mechanism that the determination of positive long-term growth depends on $(\rho / \xi)-\alpha$. Thus, high $\beta$ and low $\rho$ is necessary for the positive long-term growth. (Q.E.D.)

Thus, poverty traps are absent for sufficiently high $R \& D$ parameter $\xi$, namely the "spirit of capitalism" captured by $\beta$ is not effective in such cases. Alternatively, for an economy with lower R\&D efficiency, intensifying the "spirit of capitalism" enables the economy to "take off" (Rostow 1960) (See Fig. 2).

Last, we sketch the effects of larger $\beta$ on growth rate decreasing to 0 .

Proposition 3 Effects of increment of $\beta$ on growth rate is decreasing to 0 . Proof. From $\chi=\Gamma(l)$ and $\chi=\chi(l)$, we obtain

$$
\beta=-\frac{\left(l-\underline{l}_{A}\right)(l-\bar{l})}{\bar{\chi}\left(l-\underline{l}_{c}\right) l}
$$


This relationship between $\beta$ and $l$ has a one-to-one correspondence for the domain that satisfies the feasible condition for $l$. Thus, the inverse function of the above equation is also a function, which we denote as $l^{*}=l(\beta)$. Therefore, we obtain $l^{*}=l(\beta)$, and from this and the relationship of growth rate $g=\xi(1-l) \Lambda$, we can depict Fig. 3 for the case of $\xi>n$ and $l \in(0,1)$ (Panel (b) in Fig. 1). The other cases also have basically the same properties. Thus, Proposition 3 is obtained.(Q.E.D)

Thus, although Proposition 1 holds for all $\beta$, the effect of increment of $\beta$ becomes negligible for sufficiently large $\beta$.

\section{Conclusion}

This paper demonstrates the relationship between long-term growth realized by endogenous technological progress, which is proposed by Schumpeter, and the spirit of capitalism, which is proposed by Weber and captures the preference for wealth accumulation. If the efficiency of innovation is low, a larger spirit of capitalism is necessary for long-term positive growth, and the savings rate and the growth rate positively depend on this wealth preference for asset holding. Thus, a combination of the spirit of capitalism and innovation, that is, the interrelation between supply and usage of wealth, is shown to affect the long-term growth of an economy. A larger spirit of capitalism basically affects the long-term positive growth rate in a positive manner, and for an economy with a lower R\&D efficiency, but for an economy with a sufficiently high spirit of capitalism, the increment of the spirit has only a negligible effect.

This study is the first to explore this subject. As such, there are many agendas that remain for future research, such as the stability of the steady state and optimal policy analysis. More importantly, a theoretical, empirical, and simulation-based investigation needs to be conducted on the properties of wealth preference $\beta$, which is assumed to embody the spirit of capitalism and is exogenously and constantly given in this study.

\section{Acknowledgements}

I would like to thank Kensuke Teshima for his valuable comments. Any errors are the sole responsibility of the author. This work was financially supported by the Japan Society for the Promotion of Science.

\section{References}

Acemoglu, D., Johnson, S., \& Robinson, J. (2001). The colonial origins of comparative development: An empirical investigation. American Economic Review, 91(December), 1369-1401. https://doi.org/10.1257/aer.91.5.1369

Acemoglu, D., Johnson, S., \& Robinson, J. (2002). Reversal of fortune: Geography and institutions in the making of the modern world income distribution. Quarterly Journal of Economics, 117(4), 1231-1295. https://doi.org/10.1162/003355302320935025

Aghion, P., \& Howitt, P. (1992). A Model of Growth through creative destruction. Econometrica, 60, 323-351. https://doi.org/10.3386/w3223

Barro, R. (1991). Economic growth in a cross section of countries. Quarterly Journal of Economics, May, 407-443. https://doi.org/10.2307/2937943

Barro, R., \& McCleary, R. (2003). Religion and economic growth across countries. American Sociological Review, 68(5), 761-781. http://dx.doi.org/10.2307/1519761

Barro, R., \& Sala-i-Martin, X. (1995). Economic Growth. Boston: McGraw Hill.

Blum, D., \& Dudley, L. (2001). Religion and economic growth: Was Weber right? Journal of Evolutionary Economics, 11, 207-230. https://doi.org/10.1007/PL00003862

Cantoni, D. (2009). The economic effects of the Protestant Reformation: Testing the Weber hypothesis in the German lands. Job market paper.

Carroll, C. (2000). Why do the rich save so much? In J. Slemrod (ed.), Does Atlas shrug? The economic consequence of taxing the rich (pp. 465-84). Harvard University Press.

Cass, D. (1965). Optimal growth in an aggregate model of capital accumulation. Review of Economic Studies, 32, 229-243.

Cole, L. H., Mailath, G. J., \& Postlewaite, A. (1992). Social norms, saving behavior, and growth. The Journal of Political Economy, 100(6), 1092-1125. https://doi.org/10.1086/261855

Corneo, G. G., \& Jeanne, O. (1995). Status-seeking can generate long-run growth in the Solow-Cass model. Discussion Paper No. A-497 (Univ of Bonn). 
Dorius, S. F. (2012) The spirit of capitalism, economics developent, and national wealth. mimeo (PSC Reserch reports, Univ. of Michigan).

Duesenberry, J. S. (1949). Income, saving, and the theory of consumer behavior. Harvard University Press.

Durlauf, S., Kourtellos, A., \& Tan, C. M. (2006). Is God in the details? A reexamination of the role of religion in economic growth. mimeo.

Dynan, K. E., Skinner, J., \& Zeldes, S. P. (1996). Do the rich save more? manuscript, Board of Governors of the Federal Reserve System.

Easterly, W., \& Levine, R. (1997). Africa's growth tragedy: Policies and ethnic divisions. Quarterly Journal of Economics, 112, 1203-1250. https://doi.org/10.1162/003355300555466

Easterly, W., \& Levine, R. (2003). Tropics, germs, and crops: How endowments influence economic development. Journal of Monetary Economics, 50, 3-39. https://doi.org/10.3386/w9106

Futagami, K., \& Shibata A. (1998). Keeping one step ahead of the Joneses: Status, the distribution of wealth, and long-run growth. Journal of Economic Behavior \& Organization, 36, 109-126. https://doi.org/10.1016/S01672681(98)00072-9

Ghosh, S., \& Wendner, R. (2015). Pisitional preference and efficient capital accumulation when households axhibit a preference for wealth. mimeo

Gootzeit, M., Schneider, J., \& Smith, W. (2002). Marshallian recursive preferences and growth. Journal of Economic Behavior \& Organization, 49(3), 381-404. https://doi.org/10.1016/j.econmod.2008.03.003

Grossman, G., \& Helpman, E. (1991). Innovation and growth in the global economy. Cambridge: MIT Press.

Hall, R., \& Jones, C. (1996). The productivity of nations. NBER Working Paper 5812.

Inglehart, R., \& Baker, W. E. (2000). Modernization, cultural change, and the persistence of traditional values. American Sociological Review, 65(1), 19-51. https://doi.org/10.1016/j.econmod.2008.03.003

Koopmans, T. (1965). On the concept of optimal economic growth. In The Econometric Approach to Development Planning. Amsterdam: North-Holland Publishing Company.

Kurz, M. (1968). Optimal economic growth and wealth effects. International Economic Review, 9, 348-357.

Lillard, L., \& Karoly, L. (1997). Income and wealth accumulation over the lifecycle. manuscript, RAND Corporation.

Marshall, A. (1920). Principles of economics (8th ed.). Macmillan, London.

Noland, M. (2003). Religion, culture and economic performance. Working paper.

Ono, Y. (2015). Growth, secular stagunation and weath preference. Discussion Paper No.946, Osaka University.

Pan, S., Zhang, M., \& Zou, H. (2016). Status preference and the effects of patent protection: Theory and evidence. Macroeconomic Dynamics. https://doi.org/10.1017/S1365100516000420

Rehme, G. (2017). Love of Wealth' and Economic Growth, mimeo.

Romer, P. (1990). Endogenous technological change. Journal of Political Economy, 98, S71-S102. https://doi.org/10.1086/261725

Rostow, W. W. (1960). The Stages of Economic Growth: A Non-Communist Manifesto. Cambridge University Press.

Sachs, J. (2003). Institutions don't rule: Direct effects of geography on per capita income. NBER Working Papers 9490.

Sala-i-Martin, X., Doppelhofer, G., \& Miller, R. (2004). Determinants of long-term growth: A Bayesian averaging of classical estimates (BACE) approach. The American Economic Review, 94(4), 813-835. https://doi.org/10.1257/0002828042002570

Schumpeter, J. (1912). Theorie der wirtschaftlichen Entwicklung: Eine Untersuchung "uber Unternehmerwinn, Kapital, Kredit, Zins und den Konjunkturzyklus, in German.

Solow, R. (1957). Technical change and the aggregate production function. Review of Economics and Statistics, 39, 312-320. https://doi.org/10.2307/1926047

Weber, M. (1904/1905). Die protestantische Ethik und der Geist des Kapitalismus, in German. 
Xenos, C. N. (1989). Scarcity and modernity. New York, Routledge, Chapman and Hall.

Zhou, G. (2016) The spirit of capitalism and rational bubbles. Macroeconomic Dynamics, 20(6), 1432-1457 https://doi.org/10.1017/S1365100514000972

Zou, H. (1994). The spirit of capitalism and long-run growth. European Journal of Political Economy, 10, 279-293. https://doi.org/10.1016/0176-2680(94)90020-5

Zou, H. (1995). The spirit of capitalism and saving behavior. Journal of Economic Behavior and Organization, 28, 131-143. https://doi.org/10.1016/0167-2681(95)00024-2

Zou, H. (1998). The spirit of capitalism, social status, money, and accumulation. Journal of Economics, 68(3), 219-233. https://doi.org/10.1007/BF01237193

\section{Notes}

Note 1. The counterpart of this may be Japanese confucianism, and the frontier spirit in the US.

Note 2. A similar concept was proposed by Marshall (1920), namely, the act of saving can itself confer utility, and this concept is modelized by Gootzeit et al. (2002) by assuming a variable subjective discount rate with decreasing by saving. We can also refer to Duesenberry (1949) as an important earlier study in this field.

Note 3. This approach shares the same direction of rising behavior economics. Since humans are considered social animals, they live not only for consumption but also for some other factors. In particular, in this study, we focus on wealth accumulation, which would provide, for example, prestige and social status. These effects were emphasized by classical economists, for example, David Hume, Adam Smith, John Stuart Mill, Thorstein Veblen, and Karl Marx. The works of these classical economists, or economic philosophers, are discussed in, for example, Xenos (1989) in his "Scarcity and modernity." Further, this concept has been modeled by modern economists, for example, Corneo and Jeanne (1995), and Futagami and Shibata (1998). In these theoretical studies, wealth and/or relative consumption provide the direct utility on the household. We refer to recent studies following this line, such as Ghosh and Wendner (2015), Ono (2015) and Pan et al. (2016), among others.

Note 4. The development of endogenous growth stimulates the momentum of clarification for source of growth, and many empirical researches on the determinants of economic growth (e.g., Barro, 1991) have been executed. In this line, cultural factors have also intrigued economists. This literature isolates a number of variables that predict the subsequent rates of economic growth. One general conclusion that can be drawn is that successful explanations of economic growth must surpass narrow measures of economic variables and encompass political and social forces (e.g., Hall \& Jones, 1996; and Sala-i-Martin et al., 2004). Some researchers (e.g., Inglehart \& Baker, 2000) argue that a nation's culture should be included in a rationalization of its economic growth. Religion is an important dimension in the explanations of such literature, including geography (Sachs, 2003), institution (Acemoglu, Johnson, \& Robinson, 2001, 2002), ethnic heterogeneity (Easterly \& Levine, 1997), and climate (Easterly \& Levine, 2003). Thus, our concern here also shares the direction with modern economics for clarification of the determinants of growth.

Note 5. This assumption implies that the width of one innovation is sufficiently large. If $1 / \alpha<\lambda$, the optimal pricing is given as $p(i)=\lambda \eta$. This pricing does not alter the main framework of the model; therefore, we assume that $1 / \alpha<\lambda$ throughout this study.

Note 6. $L$ and $Q$, respectively, are the quantitative and qualitative indices as shown by the final goods production in (8), where the linear relationship between population and quality, and GDP can be obtained. Therefore, (12) implies that $R \& D$ success depends on a positive aggregate quality level and private $R \& D$ input, and on a negative economic quantitative scale and private quality level.

Note 7. $\chi(1)>0$ is immediately proved as follows:

$$
\chi(1)=\frac{\alpha \xi+\left(1-\alpha^{2}\right) n}{\frac{1-\alpha}{\xi}(n-\xi)+1}=\frac{\alpha \xi+\left(1-\alpha^{2}\right) n}{(1-\alpha) n+\alpha \xi} \xi>0
$$

Note 8 . The calculations are given as follows:

$$
\begin{gathered}
\underline{l}_{c}-\underline{l}_{v}=\frac{\alpha^{2} \Lambda \xi+\alpha^{2}(1+\alpha+\Lambda) \mathrm{n}}{\bar{\chi}(1+\alpha) \xi}>0, \\
\underline{l}_{v}-\underline{l}_{A}=\frac{\alpha^{2}}{(1+\alpha)} \frac{\xi-\mathrm{n}}{\xi}>0
\end{gathered}
$$




\section{Appendix}

\section{A. Optimization on the household with wealth preference}

The representative agent in this economy is assumed to have the following utility:

$$
U=\int_{0}^{\infty} u(c, A) e^{-\rho t} d t
$$

where $\rho$ and $u(c, A)$ are the subjective discount rate and an instantaneous utility function of the representative household, respectively. The representative household has the following budget constraint:

$$
\dot{A}=r A+w-c-n A .
$$

The optimal policy for the representative agent is to maximize (28) under the constraint (29). The Hamiltonian is given as

$$
\mathrm{H}(t)=u(c(t), A(t))+\lambda(t)\{r(t) A(t)+w(t)-c(t)-n A(t)\} .
$$

We obtain the following FOCs:

$$
\begin{gathered}
\frac{\partial \mathrm{H}(t)}{\partial c(t)}=\frac{\partial u(c(t), A(t))}{\partial c(t)}+\lambda(t)(-1)=0 \\
\rho \lambda(t)-\dot{\lambda}(t)=\frac{\partial H(t)}{\partial A(t)}=\frac{\partial u(c(t), A(t))}{\partial A(t)}-\lambda(t)(r(t)-n)
\end{gathered}
$$

The transversality condition is given as follows: $\lim _{t \rightarrow \infty} \lambda(t) A(t)=0$

From these conditions, we obtain the Euler equation as follows:

$$
\rho-\frac{\dot{\lambda}(t)}{\lambda(t)}=r(t)-n+\frac{u A(c(t), A(t))}{u c(c(t), A(t))}
$$

We specify the instantaneous utility function as (28). Using this specification, the above equation is rewritten as

$$
\left\{\sigma+\frac{\beta}{1+\beta}(1-\sigma)\right\} \frac{\dot{c}(t)}{c(t)}-\frac{\beta}{1+\beta}(1-\sigma) \frac{\dot{A}(t)}{A(t)}+\rho=r(t)-n+\beta \frac{c(t)}{A(t)}
$$

\section{B. Determination of $l^{*}$}

(24) and (25) determine the steady state labor allocation $l^{*}$. We can easily verify that $\Gamma$ is a decreasing linear function, and has a positive $\chi$-intercept, namely $\Gamma(0)>0$, and a fixed point $(\bar{l}, 0)$, where $\bar{l} \equiv \frac{1+\sigma \Lambda+\rho / \xi}{1+\alpha+\sigma \Lambda}(>0)$. $\bar{l}>1$ holds for a sufficiently small $\xi(\xi<\rho / \alpha)$, and $\bar{l} \in(0,1)$ holds for a sufficiently large $\xi(\xi>\rho / \alpha)$. As $\xi$ can be considered the R\&D efficiency, the former case corresponds to the economy with low R\&D efficiency, and the latter case corresponds to the one with high R\&D efficiency.

$\chi(l)$ is a non-linear function with $\chi(0)=0$ and $\chi(1)>0$. (Note 7) From the definition of $\chi$, we have two feasibility conditions on $c^{*}$ and $A^{*}$, which are derived as

$$
\begin{gathered}
c^{*}>0 \Rightarrow l>\frac{\left(1+\alpha^{2} \Lambda\right) \xi-\left(1-\alpha^{2}\right) n}{\bar{\chi} \xi}\left(\equiv \underline{l}_{c}\right), \\
A^{*}>0 \Rightarrow l>\frac{1-\alpha}{\xi}(\xi-n)\left(\equiv \underline{l}_{A}\right)
\end{gathered}
$$

where $\bar{\chi} \equiv 1+\alpha+\alpha^{2} \Lambda$

Furthermore, we also have an additional non-negativity condition given in (23). Therefore, the steady state conditioned by (24) and (25) must satisfy $l>\max \left\{0, \underline{l}_{c}, \underline{l}_{A}, \underline{l}_{v}\right\}$.

We can easily show that $\underline{l}_{c}>\underline{l}_{v}>\underline{l}_{A}>0$, (Note 8 ) and in this case we obtain the condition $l>\underline{l}_{c}$.

The condition $\underline{l}_{c}>\underline{l}_{A}$ and differentiating $\chi(l)$ yield the following:

$$
\frac{d \chi(l)}{d l}=\bar{\chi} \xi\left[1+\frac{\left(\underline{l_{c}}-\underline{l}_{A}\right) \underline{l}_{A}}{\left(l-\underline{l}_{A}\right)^{2}}\right]>0
$$

This demonstrates that $\chi(l)$ is increasing.

The panels (a) and (b), respectively, denote the cases of $\bar{l}>1$ and $\bar{l} \in(0,1)$. In panel (b), we use $\bar{l}>\underline{l}_{c}$ for 
all $\underline{l}$. This is shown as follows. The case of $\underline{l}_{c}<0$ is trivial because $\bar{l}>0$. Further, the case of $\underline{l}_{c} \in(0,1)$ is also illustrated by the following simple calculation:

$$
\bar{l}-\underline{l}_{c}=\frac{\alpha^{2}(1-\alpha) \Lambda}{\bar{\chi}(1+\alpha+\alpha \Lambda)}+\frac{\rho}{\bar{\chi} \xi}+\frac{\left(1-\alpha^{2}\right) n}{\xi(1+\alpha+\alpha \Lambda)}>0
$$

By taking account of $\chi\left(\underline{l}_{c}\right)=0, \Gamma(\bar{l})=0, \bar{l}>\underline{l}_{c}$, and the slopes of $\Gamma(l)$ and $\chi(l)$, the two functions $\Gamma(l)$ and $\chi(l)$ are depicted in Fig. 1, and we can confirm that these two functions have an intersection point, which satisfies the non-negativity condition $l>\underline{l}_{c}$.

If $\xi<n$, namely, $\xi<\frac{1-\alpha^{2}}{\left(1+\alpha^{2} \Lambda\right)} n<n$, we obtain $0>\underline{l}_{A}>\underline{l}_{c}>\underline{l}_{v}$. Thus, graphs of $\Gamma(l)$ and $\chi(l)$ are depicted as Fig. $1(c)$. In this case, (30) is rewritten as

$$
\frac{d l^{*}}{\partial \beta}=-\chi\left(l^{*}\right)\left[\bar{\Gamma}+\frac{l\left(1-2 \underline{l}_{A}\right)+\underline{l}_{c} \underline{l}_{A}}{\left(l-\underline{l}_{A}\right)^{2}} \beta \bar{\chi} \xi\right]^{-1}>0
$$

where the sign is derived by $1-2 \underline{l}_{A}>0$ and $\underline{l}_{c} \underline{l}_{A}>0$.

Thus, we can conclude that the discussion under $\xi>n$ basically holds under $\xi<n$ as it is.
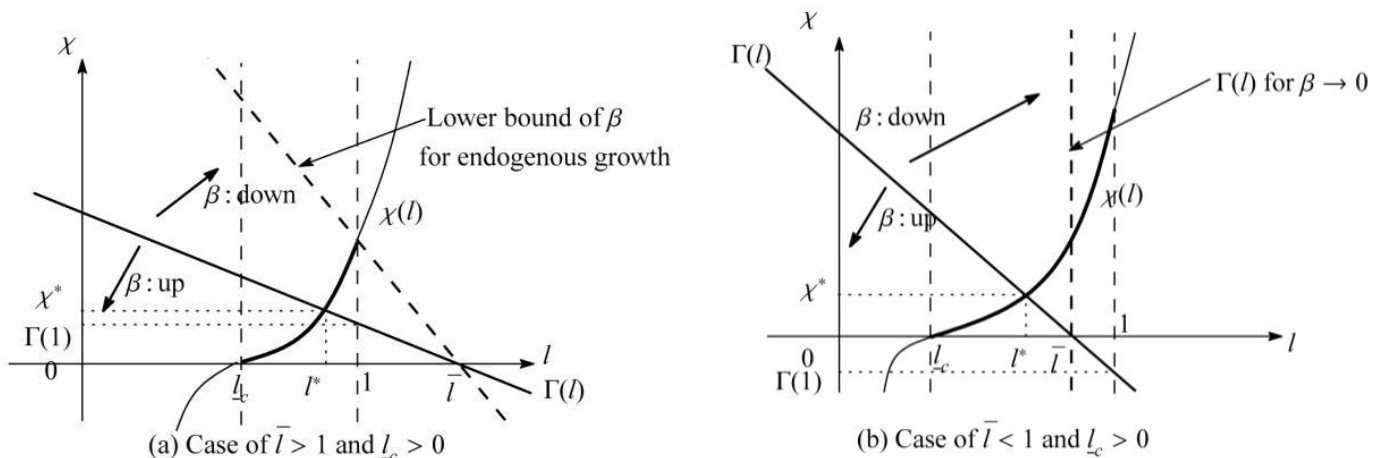

(b) Case of $\bar{l}<1$ and $l_{c}>0$

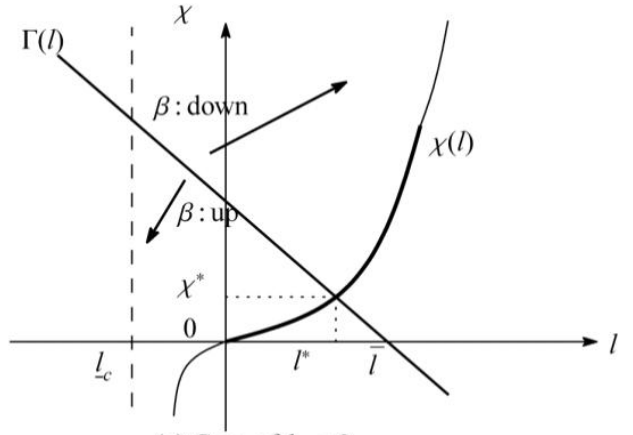

(c) Case of $\underline{l}_{c}<0$

Figure 1. Determination of $l^{*}$

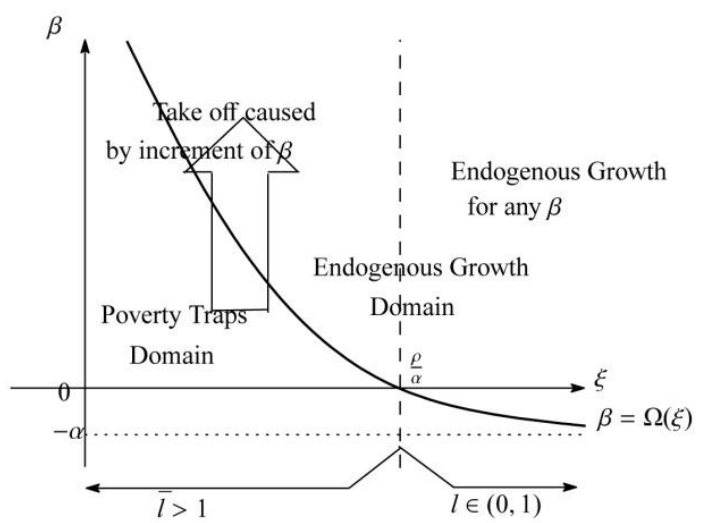

Figure 2. Relationship between parameter $\{\zeta, \beta\}$ and growth phase 


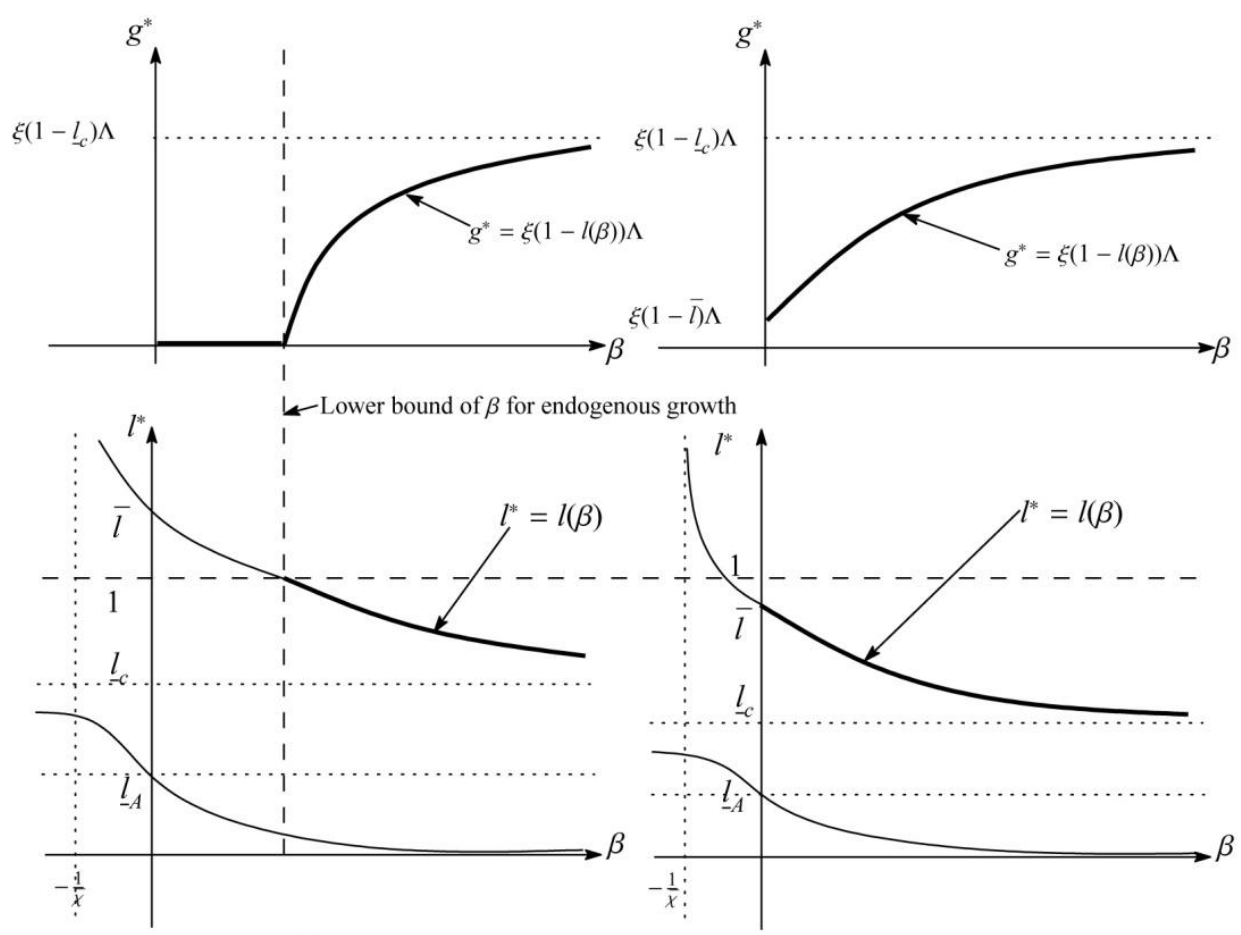

$\begin{array}{ll}\text { (a) Case of } \bar{l}>1 \text { and } \underline{l}_{c}>0 & \text { (b) Case of } \bar{l}<1 \text { and } \underline{l}_{c}>0\end{array}$

Figure 3. Relationship between parameter $\beta, l^{*}$ and growth rate

\section{Copyrights}

Copyright for this article is retained by the author(s), with first publication rights granted to the journal.

This is an open-access article distributed under the terms and conditions of the Creative Commons Attribution license (http://creativecommons.org/licenses/by/4.0/). 